\title{
Strengths and Challenges for Medical Students and Residents in Rural Japan
}

Ryuichi Ohta, MD, MHPE; Yoshinori Ryu, MD; Takuji Katsube, MME; Yoshihiro Moriwaki, MD, PhD; Jun Otani, MD, PhD

\begin{abstract}
BACKGROUND AND OBJECTIVES: In Japan, family medicine training is driven by community-based medical education (CBME) and is often provided in rural community hospitals and clinics. Although CBME's positive relationship to family medicine in rural community hospitals is proven, the learning processes of medical students and residents in rural community hospitals needs investigating. The objective of this study was to reveal medical students' and residents' changing motivations and learning behaviors, as well as the factors underpinning their transition between medical schools or tertiary hospitals and rural community hospitals.
\end{abstract}

METHODS: Over 2 years, the researchers conducted one-on-one interviews with 50 medical students and $\mathbf{3 0}$ residents participating in family medicine training at a rural community hospital, and analyzed the difficulties the participants encountered and how they overcame them. The interviews were audio recorded and transcribed verbatim. We used grounded theory in the data analysis to clarify the findings.

RESULTS: Three key themes emerged: educational background, changing environment, and factors driving the learning cycle. Participants had difficulties in overcoming differences between their previous education and their CBME, particularly regarding expected roles and the variety of medical issues. They overcame their difficulties through cognitive apprenticeships and legitimate peripheral participation enhanced by daily reflection.

CONCLUSIONS: In rural community hospitals, participants struggled to adapt to the wider practice range and the more interactive relationship with educators. Cognitive apprenticeships and legitimate peripheral participation, supported by constant reflection between learners and clinical teachers, can facilitate learning, leading to more effective learning and practice of family medicine in rural areas.

(Fam Med. 2021;53(1):32-8.)

doi: 10.22454/FamMed.2021.308872

C omprehensive health care is vital in aging societies. ${ }^{1}$ Family medicine is an important medical specialty for providing comprehensive care because family doctors are trained to manage multiple health concerns from a

serspective. ${ }^{2,3}$ Due the importance of providing comprehensive health care, training more family doctors is encouraged internationally. ${ }^{4,5}$ However, family physician training in aging societies is often underfunded and low-quality, especially in Japan where it has only been a medical specialty since $2018{ }^{6}$

Community-based medical education (CBME) is an important part of family medicine training. ${ }^{7}$ It teaches many aspects of medical care practiced by family physicians and encourages medical students and residents to become family physicians in rural areas. ${ }^{8}$ CBME focuses on family medicine to improve the quality of care and increase the number of family physicians. ${ }^{9}$ However, education provided in medical schools and tertiary hospitals is very different from that in rural community hospitals; this makes the learning process difficult for students and residents when entering the community hospital environment. ${ }^{10,11}$ Aligning the education methods of both contexts to correspond with each other is imperative in improving learning outcomes.

Previous studies have investigated CBME learning outcomes in Japan, but there is a lack of research on the learning processes behind such outcomes. ${ }^{12,13}$ In Japanese rural CBME, various difficulties arise from the differences between the education offered in universities and tertiary hospitals, and that provided in community hospitals. ${ }^{14}$ Understanding
From Community Care, Unnan City Hospital, Unnan, Shimane Prefecture, Japan (Drs Ohta, Ryu, and Katsube); Surgery, Unnan City Hospital, Unnan, Shimane Prefecture, Japan (Drs Moriwaki and Otani). 
the learning processes in rural community hospitals can help teachers develop effective curricula for medical students and residents, thereby reducing the challenges that they face during CBME and consequently increasing their motivation to become family physicians. This study aimed to reveal medical students' and residents' changing motivations and learning processes, as well as the factors underpinning their transition between medical schools or tertiary hospitals and rural community hospitals.

\section{Methods \\ Participants}

Between April 2017 and December 2019, 51 medical students and 35 residents were assigned to and participated in the CBME curriculum that included family medicine, at a rural community hospital in Japan. The training aimed to produce competencies in the required general medicine areas in Japan, such as person-centered care, comprehensive and integrative approach, interprofessional work, community orientation, professionalism, and systematic practice. Ultimately, 50 medical students and 30 second-year residents participated in this study; one student and five residents stopped training due to illness.

During their training, the participants worked with family physicians at community hospitals and clinics to learn about the most frequent illnesses and how they were managed through systematic practice and person-centered care - a comprehensive and integrative approach. They collaborated with care managers and home care workers to learn about interprofessional work, a competency expected of family physicians. In community care settings, they participated in activities to learn about rural people, such as discussions about public health from the perspectives of person-centered care and community orientation. To promote their learning, the participants reflected on their performance through 10- to 15-minute discussions with their teachers at the end of each day.

\section{Setting}

In Japan, all fifth-year medical students receive 2 weeks of mandatory clinical training in general medicine at rural community hospitals or clinics. In the sixth year, this training is conducted during a 1- or 2-month program. At the Japanese Medical University where the participants studied, family physicians are limited to emergency room care and do not regularly visit clinics; however, family physicians at the community hospitals and clinics cater to a wide range of medical problems. ${ }^{14}$

In Japanese postgraduate medical education, all residents undergo 2 years of mandatory training (at general hospitals and their affiliated institutions) on theoretical knowledge and clinical skills and attitudes regarding various medical situations. During the second year, they must spend 1 month training at community hospitals, clinics, or public health centers to learn about communitybased medicine.

The rural community hospital is located in one of Japan's most remote areas and is one of the community hospitals used for CBME in the prefecture. The city population was 38,882 in 2017 , with $37.82 \%$ over 65 years of age. At the time of the study, the rural area had 16 clinics, 12 home care stations, three visiting nurse stations, and one rural community hospital. Three doctors specialized in family medicine or primary care, treated inpatients and outpatients, and taught medical students and residents.

In line with the mandatory curricula, fifth- and sixth-year medical students and second-year postgraduate medical residents underwent more than 2 weeks of training in family and rural medicine at the rural hospital. Prior to participation, they completed basic clinical medicine studies and passed an examination on the subject. They also passed a mandatory objective structured examination on clinical care before engaging in patient care.

\section{Data Collection}

We obtained through in-person, private, semistructured interviews conducted on the last day of each participant's training. Each interview lasted about 40 minutes. Additionally, the teachers (ie, the study researchers) took field notes during their daily reflections. One researcher conducted the interviews, and two researchers conducted daily reflections. All interviews were audio-recorded and transcribed verbatim. Participants described their previous experiences in detail, including the difficulties they encountered in the CBME and their strategies to overcome these difficulties. As they reflected on their daily performance, they described their accomplishments, mistakes, emotions, and plans.

\section{Data Analysis}

Data were analyzed using constant comparison. Two researchers reviewed the transcripts and notes, and looked for frequently used phrases. Next, they searched the chosen phrases for recurring ideas and concepts, which were conceptually grouped (open coding). They consistently sought relationships among phrases, concepts, and ideas, and identified emerging themes and connected ideas, which resulted in categorization (axial coding) of the data. Throughout this process, the researchers discussed the themes and categories.

Themes about difficulties, ways to overcome difficulties, and what the researchers learned from the initial transcript reviews were explored in depth in subsequent one-on-one interviews and reflections. After we iteratively finalized teh coding scheme, two researchers separately coded all the transcripts and compared their coding choices. One researcher (R.O.) took notes on the researchers' discussions. We investigated the underlying concepts and their relationships 
in the context of relevant previous studies, and we discussed until a consensus was reached. Finally, each researcher created a model for each concept that displayed its categories, influential factors, and their relationships (Figure 1).

\section{Ethical Approval}

The study was explained to the participants and their informed written consent was obtained. They were informed that participation was voluntary, that they could withdraw at any time and for any reason without repercussions, their responses would be confidential, and that the interview data would be accessible only to the researchers. The Unnan City Hospital Clinical Ethics Committee approved the study (approval number: 20190005).

\section{Results}

All 50 medical students and 30 second-year residents who completed the CBME curriculum agreed to participate and were interviewed over 2 years. All students and residents participated in the entire curriculum. Among the students, the mean age was 23.4 years $(\mathrm{SD}=0.71)$, and approximately $64 \%(\mathrm{n}=32)$ were male. Among the residents, $60 \%(n=18)$ were male, and the mean age was 26.3 years $(\mathrm{SD}=1.51)$. The analysis revealed three main themes: (1) educational background, (2) changing environment, and (3) driving the learning cycle. Table 1 presents the themes and concepts.

\section{Educational Background}

Disease-Oriented Learning. The students stated that in the medical schools and tertiary hospitals, doctors diagnosed most of the patients and studied the pathophysiology and treatments of the diagnosed diseases. Participants lacked experience in diagnosing patients based on symptoms and clinical reasoning. Disease-oriented learning interfered with their learning about the relationship between symptoms and diseases, which challenged their clinical reasoning skills. The students and residents had to learn to make diagnoses independently, and this selfteaching became a learning style based primarily on textbooks with few clinical experiences.

Emphasis on Medical Testing. Participants indicated that their previous experiences with medical testing in medical schools and tertiary hospitals required sophisticated technologies and the educational focus was on understanding the tests and reading test results. This approach impeded their abilities to develop clinical reasoning skills and function well at the community hospitals. Therefore, they were unprepared to diagnose diseases based on patients' symptoms and physical examinations.

\section{Clinical Situations Specific to} Acute Care. Medical schools and tertiary hospitals focused on training the study participants in acute and specialized care. Most of the patients were treated for a few weeks and then discharged. The participants had never worked with long-term care patients or general diseases, and many stated that they felt challenged by the broad scope of situations presented in family medicine.

\section{Limited Role on a Clinical Team.}

At the medical schools and tertiary hospitals, participants often observed their teachers treating patients, or assisted with treatment by following their teachers' instructions. They worked in large teams and did not individually treat patients. Their role was to report or interpret the doctors' treatments, leading to

Figure 1: The Concept Model

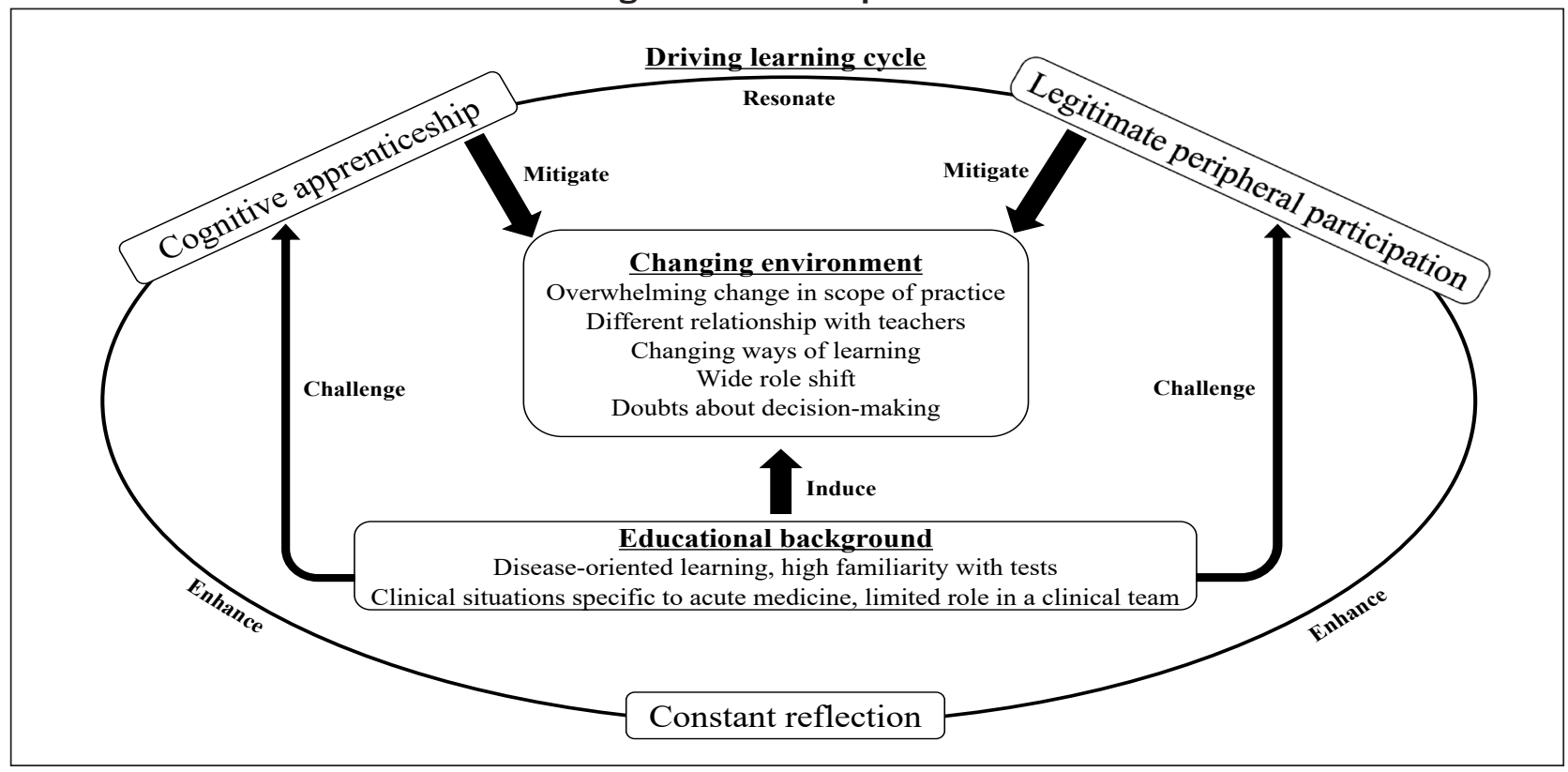


Table 1: Three Themes and Their Concepts Using Grounded Theory Methodology

\begin{tabular}{|c|c|c|}
\hline Theme & Concept & Sample Participant Quote \\
\hline \multirow{4}{*}{$\begin{array}{l}\text { Educational } \\
\text { background }\end{array}$} & $\begin{array}{l}\text { Disease- } \\
\text { oriented } \\
\text { learning }\end{array}$ & $\begin{array}{l}\text { The diseases we studied in medical universities are very complicated. Though we were } \\
\text { encouraged to learn about diseases in terms of symptoms and physical examinations, we } \\
\text { tended to learn only treatment and prognosis. (Student 5) }\end{array}$ \\
\hline & $\begin{array}{l}\text { Emphasis on } \\
\text { medical testing }\end{array}$ & $\begin{array}{l}\text { There are a lot of difficult tests to diagnose complicated diseases. In my university, } \\
\text { physicians discussed how to interpret test results, not symptoms. So, we tried to } \\
\text { understand their discussions and focused on tests. (Resident 16) }\end{array}$ \\
\hline & $\begin{array}{l}\text { Clinical } \\
\text { situations } \\
\text { specific to } \\
\text { acute care }\end{array}$ & $\begin{array}{l}\text { In our hospital, most patients' treatments are decided based on set practices and specific } \\
\text { durations. We thought that patients everywhere were discharged at set times. I never } \\
\text { imagined that so many patients would require adjustment to their original discharge } \\
\text { time. (Resident 23) }\end{array}$ \\
\hline & $\begin{array}{l}\text { Limited role on } \\
\text { a clinical team }\end{array}$ & $\begin{array}{l}\text { In my hospital, we are supposed to follow senior physicians when we determine the } \\
\text { patient management plan. Our role is to report patients' conditions to them. Though we } \\
\text { can discuss patients' treatments with them, they ultimately decide without our input. } \\
\text { The learning situations in the community hospital were completely different in terms of } \\
\text { participation level. The medical team was small, and there were more collaborations with } \\
\text { senior physicians and medical teachers. (Student 27) }\end{array}$ \\
\hline \multirow{5}{*}{$\begin{array}{l}\text { Changing } \\
\text { environment }\end{array}$} & $\begin{array}{l}\text { Scope of } \\
\text { practice }\end{array}$ & $\begin{array}{l}\text { I have never experienced multiple diseases in a single learning setting. At this hospital, } \\
\text { I examined different categories of diseases. Although the experience was exciting, I was } \\
\text { confused about how to approach patients and by the broadness of the learning content, } \\
\text { including different organs and systems. I even treated chronically bed-ridden patients } \\
\text { waiting for discharge, home care patients, and patients with acute infections and heart } \\
\text { failure. I was also overwhelmed with the varieties of family medicine. (Student 34) }\end{array}$ \\
\hline & $\begin{array}{l}\text { Relationships } \\
\text { with teachers }\end{array}$ & $\begin{array}{l}\text { As a student, I never discussed patients' issues interactively with clinical teachers. I } \\
\text { interacted with them only in lectures and small discussions. I felt at a distance from } \\
\text { them. This was created by the situations in medical hospitals because clinical teams } \\
\text { are big, and interactions between members are scant. At the community hospital, I had } \\
\text { frequent opportunities to discuss medical issues with clinical teachers. I was surprised } \\
\text { at the difference in the relationship with clinical teachers and needed time to change my } \\
\text { learning attitude. (Student 23) }\end{array}$ \\
\hline & $\begin{array}{l}\text { Ways of } \\
\text { learning }\end{array}$ & $\begin{array}{l}\text { In universities, we learned medicine mainly from textbooks. Of course, I treated several } \\
\text { cases where patients were allocated by clinical teachers, but I was not able to visit the } \\
\text { patients frequently because I felt distant from them. In the community hospital, we } \\
\text { accompanied clinical teachers every day to check patients' conditions and were used to } \\
\text { seeing patients. Every time I saw patients, I had several questions and had to consult the } \\
\text { textbooks. It is very different from learning in universities. (Resident 3) }\end{array}$ \\
\hline & $\begin{array}{l}\text { Role } \\
\text { expectations }\end{array}$ & $\begin{array}{l}\text { At the community hospital, the range of what we could do toward patients' care } \\
\text { became wide. Clinical teachers gave us various tasks to do. These were interesting } \\
\text { and challenging. However, as the change was relatively drastic, I became confused and } \\
\text { anxious about the safety of patients and the quality of care. (Resident 10) }\end{array}$ \\
\hline & $\begin{array}{l}\text { Leadership } \\
\text { for medical } \\
\text { treatment or } \\
\text { management }\end{array}$ & $\begin{array}{l}\text { At first, I had great difficulty making decisions about patients. Of course, I had already } \\
\text { made several decisions about patient management with senior doctors, but after } \\
\text { reflecting on those experiences, I think I just followed the senior doctors' decisions. At } \\
\text { the community hospital, I had several opportunities to determine patient treatments in } \\
\text { cooperation with the clinical teachers. Compared to the university, because the clinical } \\
\text { team was small, my discretionary power was relatively high. I was motivated to challenge } \\
\text { the decision-making, but the experiential gap between community hospitals and tertiary } \\
\text { hospitals might be too large. (Student 17) }\end{array}$ \\
\hline
\end{tabular}


Table 1: Continued

\begin{tabular}{|c|l|l|}
\hline Theme & \multicolumn{1}{|c|}{ Concept } & \multicolumn{1}{c|}{ Sample Participant Quote } \\
\hline \multirow{5}{*}{$\begin{array}{l}\text { Driving the } \\
\text { learning } \\
\text { cycle }\end{array}$} & \begin{tabular}{l} 
Cognitive \\
apprenticeship \\
\cline { 2 - 3 }
\end{tabular} & $\begin{array}{l}\text { Legitimate } \\
\text { peripheral } \\
\text { participation } \\
\text { with patients and colleagues and their examinations and decision-making. I had never } \\
\text { before frequently observed senior doctors. So, at the community hospital, I was able to } \\
\text { learn based on actual cases. Furthermore, while I observed them, they gave me advice on } \\
\text { clinical issues, which enhanced my learning about family medicine. (Resident 29) }\end{array}$ \\
\cline { 2 - 4 } & $\begin{array}{l}\text { Accomplishing tasks at the community hospital was very difficult because I did not } \\
\text { previously complete all those tasks independently, but the clinical teachers gave me } \\
\text { advice for completing them. Although all tasks felt huge, I was able to finish them by } \\
\text { taking the suggested steps. I feel that gradual participation in a clinical team and a } \\
\text { stepwise progression might be effective for this training. (Resident 21) }\end{array}$ \\
\hline $\begin{array}{l}\text { Regular } \\
\text { reflection }\end{array}$ & $\begin{array}{l}\text { The teachers gave us time to reflect on our learning each day. In each reflection, I could } \\
\text { ask questions and discuss ways to manage my patients. As I confessed to some difficulties } \\
\text { in learning, the teachers advised me and adjusted their teaching. By reflecting every day, } \\
\text { I established productive relationships with the teachers, which enabled me to ask more } \\
\text { questions and actively participate in the training. (Student 2) }\end{array}$ \\
\hline
\end{tabular}

hesitation in taking a leading role during CBME because of the drastic changes in their role in a rural community hospital.

\section{Changing Environment}

Scope of Practice. During CBME, the participants were exposed to a wide range of medical problems. They treated patients in the acute, chronic, and terminal stages of disease. While the broad scope of practicing family medicine was interesting to the participants, they had difficulty with CBME because their exposure to new medical problems and diseases at varying stages demanded new ways of thinking and reasoning.

Relationships With Teachers. Interactions between the participants and their teachers at the community hospital were more frequent than they had previously experienced. In medical schools and tertiary hospitals, the participants were members of large teams, therefore they had few opportunities for continuity in patient care and instruction by the same teachers. They described feeling distant from their teachers and were unaccustomed to frequently discussing patients with them. The different types of relationships they experienced with their CBME teachers challenged their learning styles by forcing them to shift from a passive to an interactive style.

Ways of Learning. Before entering the CBME program, the student participants had primarily learned from textbooks and a large number of simulated cases. Their experience with real cases was limited. However, CBME offered opportunities for them to interact with and learn from patients with diverse illnesses. They needed to alternate between patients and textbooks more often, and the interactive situations with clinical teachers led to more clinically-oriented learning styles. Due to their frequent interactions with patients, they had many questions that required answers. Frequent interactions with both patients and teachers reduced their sense of psychological distance from the patients.

Role Expectations. As opposed to the large teams in medical schools and hospitals, CBME's small clinical teams allowed students to participate in patient management. Every clinical round with their teachers resulted in several tasks that had to be accomplished by a certain time with respect to patient care. Students were motivated to fulfill their roles but were anxious about performing the tasks due to concerns about patient safety and quality of care. At the beginning of the CBME, the students and residents needed to adapt their perspectives on learning and participating in the training.

Leadership for Medical Treatment or Management. During the CBME, students and residents needed to make responsible decisions about patient management. Although they stated that their teachers supported them, they lacked confidence because they were used to following senior doctors' instructions. Working in small clinical teams enabled them to participate in patient management directly. However, the gap between educational contexts was large enough for them to perceive it as a major obstacle.

\section{Driving the Learning Cycle}

Cognitive Apprenticeship. During CBME, participants accompanied and observed their teachers more than they had in tertiary hospitals. Their frequent discussions with teachers enhanced their understanding of the cognitive apprenticeship. The participants stated that they perceived a large difference regarding patient care between the community hospital and their previous hospital. They gained new ways of learning by observing their teachers and receiving constant feedback, which helped reduce their hesitation 
toward participating in the training. The students gained knowledge and skills through regular interactions with their teachers in a cognitive apprenticeship context. They were novices in family medicine, but through multiple clinical experiences with their teachers, they became active participants.

Legitimate Peripheral Participation (LPP). During the CBME, the students had a comprehensive role in performing patient care than at their previous hospital. LPP was enhanced by cognitive apprenticeship and constant communication with teachers. Although they stated that they were challenged by the role, participants gradually integrated and became active members of the clinical teams at the community hospital. When they had difficulties accomplishing tasks, their teachers provided advice and guidance.

Regular Reflection. The participants discussed their role with the teachers daily. The teachers engaged them in discussions about patient management, during which the students reflected on their feelings and challenges. This process helped them understand how the teachers perceived their roles and how to fulfill their demands. The teachers modified their teaching styles and ways of interacting with the participants based on the reflections. The daily reflections encouraged participation by increasing the desire to learn and participate in the training. Regular discussions between the participants and teachers strengthened their relationships, which enhanced the participants' learning via cognitive apprenticeship and LPP.

\section{Discussion}

This study shows that medical students and residents experienced difficulties in community hospitals due to their previous educational background. The learning environment in community hospitals broadened their scope of practice, and changed their learning styles and relationships with teachers, as well as their roles in clinical settings. In the learning process, cognitive apprenticeship and LPP were integrated and participants' regular reflection on performance facilitated their learning of family medicine.

The present clinical education system in Japan should revise preclinical and clinical education processes to employ learning methods that teach symptom patterns and clinical reasoning. As learners did not discuss their learning with their teachers effectively, the learning situation might have led them to become passive learners. ${ }^{15}$ This study found that the learning context did not encourage students to participate actively in patient care; they mostly learned by observing and emulating senior doctors. Clinical situations in universities and tertiary hospitals can incorporate medical students and residents into their medical teams and gradually demonstrate the processes of clinical reasoning through learners' active participation. ${ }^{16}$

Family medicine instruction in community hospitals requires the development and implementation of an orientation session for CBME that prepares students for the learning environment and what is expected of them. In the CBME they received in rural community hospitals, they were gradually exposed to multiple areas of medicine and guided toward self-directed learning, which was new for them. ${ }^{17,18}$ The breadth of the medical practice and their relationships with teachers at the rural community hospitals changed participants' learning strategies, which supports the previous finding. ${ }^{14}$ The participants actively engaged in patient care with the teachers' encouragement, which helped them become self-directed learners. Previous research found that the CBME context can change students' attitudes toward learning from passive to active. ${ }^{19,20}$ Although the participants reported that learning at the community hospitals enhanced their learning of family medicine, the different learning environment and learning strategies might challenge the participants. ${ }^{21}$ These results suggest the implementation of orientation programs regarding the learning process for family medicine in community hospitals.

Cognitive apprenticeship and LPP learning methods might be systematic ways to help medical students and residents adapt and increase their self-directed learning when they begin training at rural community hospitals. Cognitive apprenticeship is a learning theory that emphasizes the transmission of knowledge and skills from master to novice while participating in clinical situations. ${ }^{22}$ According to LPP, newcomers become community members by accomplishing simple, low-risk tasks that gradually integrate them into the group. ${ }^{23}$ Both learning theories can be complementary in driving clinical education and integrating the process of reflection. ${ }^{22,23}$ Regular and planned reflection can thus support the learning process efficiently. ${ }^{24}$

Regular reflection can also mitigate difficulties caused by the difference in learning styles. This study found that preexisting learning styles were not effective and that the participants were doubtful about the appropriateness of their learning styles. Medical students tend to experience difficulties when they are introduced to new training settings. ${ }^{25}$ Reflection helped highlight individual differences among learners in terms of learning styles and concerns, and clarified their roles in clinical settings, which might have enhanced personalized teaching. ${ }^{26}$ Our study further found that supportive teacher-student relationships in rural community hospitals were important and were strengthened through daily reflections. Through the discussions between medical teachers in universities, tertiary hospitals, and community hospitals, medical students can seamlessly participate in CBME based on cognitive apprenticeship and LPP, which are reinforced by regular reflection. 
This study has limitations. The study participants were assigned to and participated in the CBME without random sampling, which may have resulted in selection bias. Another limitation was the relationship between interviewers and interviewees. The interviewers were the interviewees' teachers, thus the participants might not have openly discussed their difficulties concerning the curriculum, which could have limited the qualitative data in this research. In future studies, these limitations can be overcome by collecting comments anonymously, and subsequently using focus groups to clarify and discuss the learning processes facilitated by researchers, excluding students' educators.

During CBME in rural community hospitals, medical students and residents struggled with the scope of rural medical practice, the demands of their new roles, and confusion about their relationships with teachers. Their previous learning styles and roles did not fit the rural community hospitals. Cognitive apprenticeships and LPP approaches to teaching and learning, supported by regular reflection with teachers, might help students and residents adapt to the new environment, improve their interpersonal skills, and strengthen their self-directed learning, encouraging them to specialize in family medicine and improve rural medicine. Modifying the entire medical education process to develop clinical reasoning, and providing orientation to the rural hospital is necessary to ensure learners' success and foster a competent and independent practice for family physicians.

ACKNOWLEDGMENTS: The authors thank all the study participants.

CORRESPONDING AUTHOR: Address correspondence to Dr Ryuichi Ohta, Community Care, Unnan City Hospital, 699-1221 96-1 Iida, Daito-cho, Unnan, Shimane Prefecture, Japan. +81-9050605330. ryuichiohta0120@gmail.com.

\section{References}

1. Hone T, Macinko J, Millett C. Revisiting AlmaAta: what is the role of primary health care in achieving the Sustainable Development Goals? Lancet. 2018;392(10156):1461-1472.

2. Bazemore A, Petterson S, Peterson LE, Phillips RL Jr. More comprehensive care among family physicians is associated with lower cost and fewer hospitalizations. Ann Fam Med. 2015;13(3):206-213

3. Borrell-Carrió F, Suchman AL, Epstein RM. The biopsychosocial model 25 years later: principles, practice, and scientific inquiry. Ann Fam Med. 2004;2(6):576-582.

4. Haq C, Ventres W, Hunt V, et al. Where there is no family doctor: the development of family practice around the world. Acad Med. 1995;70(5):370-380

5. Turkeshi E, Michels NR, Hendrickx K, Remmen R. Impact of family medicine clerkships in undergraduate medical education: a systematic review. BMJ Open. 2015;5(8):e008265.

6. Japanese Board of Medical Specialties. https:// www.japan-senmon-i.jp/ (in Japanese). Accessed June 30, 2020.

7. Margolis CZ. Community-based medical education. Med Teach. 2000;22(5):482-484.

8. Somporn P, Ash J, Walters L. Stakeholder views of rural community-based medical education: a narrative review of the international literature. Med Educ. 2018;52(8):791-802.

9. Curran V, Rourke J. The role of medical education in the recruitment and retention of rural physicians. Med Teach. 2004;26(3):265-272.

10. Muller JH, Jain S, Loeser H, Irby DM. Lessons learned about integrating a medical school curriculum: perceptions of students, faculty, and curriculum leaders. Med Educ. 2008;42(8):778785.

11. Vergel J, Stentoft D, Montoya J. Extending the theoretical framework for curriculum integration in preclinical medical education. Perspect Med Educ. 2017;6(4):246-255.

12. Kato D, Wakabayashi H, Takamura A, Takemura YC. Identifying the learning objectives of clinical clerkship in community health in Japan: focus group. J Gen Fam Med. 2019;21(2):3-8.

13. Downey LH, Wheat JR, Leeper JD, Florence JA, Boulger JG, Hunsaker ML. Undergraduate rural medical education program development: focus group consultation with the NRHA Rural Medical Educators Group. J Rural Health. 2011;27(2):230-238

14. Ohta R, Ryu Y, Katsube T, Moriwaki Y, Otani J. Students' perceptions of general medicine following community-based medical education in rural Japan. J Gen Fam Med. 2019;20(6):236243.

15. Grendar J, Beran T, Oddone-Paolucci E. Experiences of pressure to conform in postgraduate medical education. BMC Med Educ. 2018;18(1):4.
16. Pinnock R, Anakin M, Jouart M. Clinical reasoning as a threshold skill. Med Teach. 2019;41(6):683-689.

17. Stalmeijer RE, Dolmans DH, Snellen-Balendong HA, van Santen-Hoeufft M, Wolfhagen $\mathrm{IH}$, Scherpbier AJ. Clinical teaching based on principles of cognitive apprenticeship: views of experienced clinical teachers. Acad Med. 2013;88(6):861-865.

18. Ten Cate TJ, Kusurkar RA, Williams GC. How self-determination theory can assist our understanding of the teaching and learning processes in medical education. AMEE guide no. 59. Med Teach. 2011;33(12):961-973.

19. Durning SJ, Artino AR. Situativity theory: a perspective on how participants and the environment can interact: AMEE guide no. 52 . Med Teach. 2011;33(3):188-199.

20. Takamura A, Misaki H, Takemura Y. Community and interns' perspectives on community-participatory medical education: from passive to active participation. Fam Med. 2017;49(7):507-513.

21. Young JQ, Van Merrienboer J, Durning S, Ten Cate O. Cognitive load theory: implications for medical education: AMEE guide no. 86. Med Teach. 2014;36(5):371-384.

22. Collins A, Brown JS, Newman SE. Cognitive apprenticeship: teaching the craft of reading, writing, and mathematics (technical report no. 403). Champaign, IL: Center for the Study of Reading, University of Illinois at UrbanaChampaign; 2007.

23. Lave J, Wenger E. Situated learning: legitimate peripheral participation. Cambridge, UK: Cambridge University Press; 1991.

24. Pagatpatan CP Jr, Valdezco JA, Lauron JD. Teaching the affective domain in communitybased medical education: a scoping review. Med Teach. 2020;42(5):507-514.

25. Egnew TR, Lewis PR, Meyers KR, Phillips WR. The Suffering Medical Students Attribute to Their Undergraduate Medical Education. Fam Med. 2018;50(4):296-299.

26. Mann KV. Theoretical perspectives in medical education: past experience and future possibilities. Med Educ. 2011;45(1):60-68. 